\title{
A questionnaire assessment of nutrition knowledge - validity and reliability issues
}

\author{
AS Anderson ${ }^{1, *}$, A Bell $^{1}$, A Adamson ${ }^{2}$ and P Moynihan ${ }^{2}$ \\ ${ }^{1}$ Centre for Public Health Nutrition Research, Department of Medicine, Ninewells Medical School, University of \\ Dundee, Dundee DD1 9SY, UK: ${ }^{2}$ Human Nutrition Research Centre, University of Newcastle, Wellcome \\ Laboratories, The Royal Victoria Hospital, Newcastle upon Tyne NE2 4LP, UK
}

Submitted 3 July 2001: Accepted 10 October 2001

\begin{abstract}
Objective: This study describes an evaluation of validity and reliability measures in a questionnaire designed to assess knowledge of applied nutrition in children participating in an after-school care dietary intervention programme being undertaken in an area of high social disadvantage.

Design: Three domains were assessed: Knowledge of Applied Nutrition (KN), Knowledge of Food Preparation (KP) and Perceived Confidence in Cooking Skills (PC). Four pilot studies were undertaken to determine item reliability, test-retest reliability, discrimination and difficulty indices, and content, cognitive and face validity.

Setting: Primary schools in Dundee, Scotland and Newcastle upon Tyne, England.

Subjects: Ninety-eight children aged 11 years.

Results: The final instrument comprised 36 questions (18 KN items, $9 \mathrm{KP}$ items and 9

PC items) presented on four sides of paper, which could be self-completed in less than 15 minutes. Question formatting included open and closed structures (KP) and multiple choice (KN and PC) items. All knowledge questions could be answered correctly by 5 to $95 \%$ of the target population, with discrimination scores ranging from 0.06 to 0.83 . Retest reliability scores were significant (KN $0.458, P<0.001$; KP 0.577 , $P<0.001$; PC 0.381, $P<0.001$ ) and internal reliability (Cronbach's alpha) of each component was also significant.

Conclusion: The test meets basic psychometric criteria for reliability and validity and forms a suitable instrument for measuring changes associated with intervention work aimed at improving food and dietary knowledge.
\end{abstract}

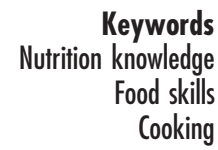

Poor dietary habits during childhood and adolescence may affect day-to-day well-being and performance, growth and development, dental health and increase likelihood of iron-deficiency anaemia ${ }^{1}$. In addition, poor childhood nutrition may increase the risks of chronic dietrelated diseases such as ischaemic heart disease and cancer $^{2}$. Research in the last decade ${ }^{3-6}$ has shown that the diets of schoolchildren provide more than the recommended amount of energy from fat (37.4-38.7\%) and fall short in the provision of a number of nutrients, in particular riboflavin, iron and calcium and dietary fibre. In turn, these nutrient profiles have been related to food choices relatively high in snack foods, confectionery, baked goods and sweetened drinks.

People living in socially deprived areas are less likely to consume a nutrient-dense diet high in complex carbohydrates, fruits and vegetables 7,8 . Children from poorer backgrounds may also find it harder to achieve a balanced diet when cultural, psychological and social factors (notably peer influences), advertising promotions and nutrition knowledge interact with economic variables. Thus attaining and maintaining good eating habits in childhood and changing existing eating patterns are major challenges for nutrition educators?

A recent review of interventions to promote healthy eating in schoolchildren ${ }^{10}$ highlighted the success of US intervention programmes ${ }^{11}$ that combined behavioural theory, school, family and community initiatives, intensive instruction delivery and self-assessments of eating behaviour. More recently, Liquori et al. $^{12}$ demonstrated the value of incorporating a cooking component in youth nutrition programmes by showing increases in nutrition knowledge, behavioural intentions and decreased plate waste. Increasingly, evidence on dietary change points to the importance of continuing nutrition education, improving skills to facilitate behavioural change and increasing access to a healthy balanced diet.

However, the process of assessing the impact of dietary 
intervention programmes is problematic. Most interventions focus on improving nutrition knowledge but there is little evidence that improving knowledge improves dietary intake. Some research ${ }^{13}$ suggests that the poor relationship between knowledge and behaviour can be explained by inaccurate measurement of the former and it is clear that a structured approach is needed ${ }^{14}$. Interventions aimed at improving knowledge about applied nutrition may be particularly difficult to assess, given that food skills are inevitably a practical domain (although it is recognised that a basic level of knowledge about ingredients, preparation methods and cooking times is also required).

The aim of this paper is to describe the reliability and validity of a questionnaire developed to assess knowledge of applied nutrition and related variables in children from low-income backgrounds participating in a practical foodskills intervention programme.

\section{Methods}

\section{Questionnaire development}

\section{Practical considerations}

The main consideration was to produce a test suitable for pre- and post-intervention assessment that could be administered in approximately 15 minutes to children aged between 10 and 13 years from low-income backgrounds who were participating in an After-School Cookery Club. This assessment comprised only one part of the overall evaluation of the intervention, which included dietary diaries (for estimating individual nutrient intake), home food purchase diaries (for estimating changes in family food choices), qualitative sociological interviews with children, and semi-structured interviews with the families' main food provider.

\section{Content domains}

Overall the questionnaire was developed to assess practical knowledge towards a healthy balanced diet as defined in the document Eight Guidelines for a Healthy Diet $^{15}$ and recent national dietary education reports ${ }^{16,17}$. To condense these topic areas, the questionnaire focused on matters relating principally to increasing intakes of bread, potatoes, cereals, fruits and vegetables, and decreasing intakes of foods high in fat such as processed meat, full-fat dairy products and fried foods. To contextualise these foods, questions were formulated with respect to eating occasions. Building on previous work on assessing nutrition knowledge ${ }^{18,19}$, three main areas related to the aims of the dietary intervention were identified:

1. Knowledge of Applied Nutrition (e.g. healthy eating options);

2. Knowledge of Food Preparation (e.g. ingredients and cooking times); and
3. Perceived Confidence in Cooking Skills (e.g. ability to prepare basic menu items)

Examples of questions on each of the knowledge and confidence sections are illustrated in Table 1.

The attitudes questions are not reported here but are available elsewhere.*

Item topics, design and format

Knowledge of Applied Nutrition items were designed to assess the relative nutrition content (described as 'healthy option') of familiar foods in everyday meal occasions. These dishes and food were initially identified at a local level $^{20}$ using menus derived from local authority schools, observations of food selections at local cafés used by young people and at national level from The Gardner Merchant School Meals Survey ${ }^{21}$. A wide range of items was identified using these approaches and the final decisions were based on which menu items might be suitable for preparation in the intervention that would serve to demonstrate a number of techniques and basic skills. It was agreed that all food items queried in the test instrument would be discussed or prepared in the intervention classes.

For each question subjects were asked to identify the most healthful choice from a list of options for various eating occasions. In the design process it was agreed that the correct answers for a 'more bealthful choice/option' were items that contained more than 50\% energy from starchy carbohydrate and less than 35\% energy from fat or made reference to fruit or vegetable content. In this section of the test questionnaire there were four questions on fruit and vegetable content, six on sources of starchy carbohydrate and eight relating to high-fat items.

Responses were presented in nine multiple-choice formats (including one graphical format of the healthiest proportion of foods) and one (nine-part) question on increased consumption. All items were scored as one point $(+1)$ for a correct answer with a maximum score of +18 .

Knowledge of Food Preparation items were designed to assess knowledge of basic food preparation and cooking skills required for preparing familiar dishes. Questions relating to 'knowledge of ingredients' were drafted with respect to commonly consumed meal items (e.g. cooked dishes planned for the intervention). The final foods selected were coleslaw, lentil soup, bread and apple crumble.

Each question was presented as an open question inviting responses on core ingredients required to prepare dishes. Blank lines indicated the number of responses

*Moynihan $\mathrm{P}$, et al. Teaching children from deprived social backgrounds food preparation using healthy foods as a means of improving their diets and the diets of their family. Report prepared for (UK) Department of Health, London, 2000. 
Table 1 Content domains and item examples

\begin{tabular}{|c|c|c|c|c|}
\hline Content domains & Item example & Options & Correct answer & Score \\
\hline $\begin{array}{l}\text { Knowledge of } \\
\text { Applied Nutrition }\end{array}$ & $\begin{array}{l}\text { Which one of the following } \\
\text { choices would NOT be a } \\
\text { good example of a healthy snack? }\end{array}$ & $\begin{array}{l}\text { Wholewheat cereal } \\
\text { Apple } \\
\text { Sausage roll } \\
\text { Toast and jam } \\
\text { Not sure }\end{array}$ & Sausage roll & +1 \\
\hline Knowledge of & What are the main & Three spaces given for & Cabbage & +1 \\
\hline Food Preparation & $\begin{array}{l}\text { ingredients needed to } \\
\text { make coleslaw? }\end{array}$ & respondent to answer & $\begin{array}{l}\text { Carrot } \\
\text { Dressing }\end{array}$ & $\begin{array}{l}+1 \\
+1\end{array}$ \\
\hline $\begin{array}{l}\text { Perceived Confidence } \\
\text { in Cooking Skills }\end{array}$ & $\begin{array}{l}\text { Without using a packet or } \\
\text { tub rate your ability at preparing } \\
\text { the following foods (e.g. pasta) }\end{array}$ & $\begin{array}{l}\text { All by myself } \\
\text { With a little help } \\
\text { With a lot of help } \\
\text { Not at all }\end{array}$ & All responses possible & $\begin{array}{r}+3 \\
+2 \\
+1 \\
0\end{array}$ \\
\hline
\end{tabular}

sought for each dish. The scoring system awarded one point for each core ingredient as follows:

- coleslaw - cabbage, carrot, a dressing (+3);

- lentil soup - lentils, onions, other vegetable, liquid (either as water or stock) $(+4)$;

- bread - flour, yeast, liquid (+3); and

- apple crumble - apples, sugar, flour, fat (+4).

The maximum possible score was +14 .

Questions relating to 'knowledge of cooking time' were drafted to reflect common meal items (vegetable stir-fry, broccoli, pasta shells, boiled white rice and boiled potatoes). Approximate cooking times were informed by manufacturers' recommended cooking instructions appearing on packets, or in standard texts ${ }^{22}$. The questions were presented in a grid format and the approximate times phrased as 'up to 15 min' and 'more than 15 min' running consecutively along the top, with the four meal items down the left-hand side.

The scoring was again one point for each correct answer as follows:

- vegetable stir-fry - up to $15 \mathrm{~min}(+1)$;

- broccoli - up to 15 min (+1);

- pasta shells (not quick-cook in water that is already boiling) - up to $15 \min (+1)$;

- white rice (not easy cook) - more than 15 min (+1); and

- boiled potatoes - more than 15 mins (+1).

The maximum score for this section (Knowledge of Food Preparation) was +5 .

Perceived Confidence in Cooking Skills items were designed to assess perceived personal ability to prepare common meal items. The items selected were identical to those in the knowledge of food preparation section (apple crumble, boiled potatoes, boiled rice, bread, broccoli, coleslaw, lentil soup, pasta shells and vegetable stir-fry). Respondents were given a (four)-category response format: 'all by myself' - 'with a little help' - 'with a lot of help' - 'not at all'.

These items were presented in a grid, the responses along the top and the seven menu items down the lefthand side.

Scoring for this section was as follows:

- 'all by myself' responses -+3 ;

- 'with a little help' responses - +2;

- 'with a lot of help' responses - +1; and

- 'not at all' responses - 0 points.

Maximum score was +27 .

\section{Validity and reliability testing}

Content validity was assessed by an independent panel of academic staff working in applied nutrition research that provided comment on the clarity and content in terms of nutritional appropriateness and cognitive complexity of the items. The food and menu items chosen were discussed in relation to familiarity but also for relevance for the intervention.

Face validity was assessed initially by individual discussion with a convenience sample of children aged 8-14 years who attended a local breakfast club. Further qualitative assessment (cognitive testing) ${ }^{23}$ was made during the reliability testing (see below) using in-depth discussion with respondents focusing on areas of confusion and poor comprehension.

Reliability testing was undertaken to ensure that components of the cognitive domains related to the total assessment (Cronbach's alpha) ${ }^{24}$ and stability over time (test-retest paradigm) for the main cognitive domains. Other reliability tests include measures of robustness such that tests can differentiate according to a range of ability, e.g. high or low knowledge. This was measured quantitatively by an item discrimination index, which measures the ability of the item to discriminate between those who do well on the test and those who do not. This is measured by correlating the score for each item with the total score. Suggested criterion for inclusion is that items should correlate with the total score beyond a value of $0.20^{25}$. A further measure is the item difficulty index, which should enable an appropriate range of results to be assessed that are neither too easy nor too difficult for the 
population under study. The indices quoted by Kline ${ }^{25}$ suggest that between 20 and $80 \%$ of the sample should answer items correctly.

\section{Format of presentation}

In its final format the test comprised four pages divided into two main sections headed 'Food Preparation and Cooking' and 'Nutrition Knowledge'.

\section{Pilot studies}

The pilot studies were undertaken for reliability and validity testing of the draft questionnaire. Three of the pilot studies were undertaken with 77 children aged 11-12 years in two primary schools in Dundee and one in a school in the Tyne \& Wear area with 21 children (12 females and 9 males) aged 11 years. Oral instructions were given to children write their name and age on the questionnaire. The children were informed that this questionnaire was not part of their schoolwork, but it was important that they did not confer with each other. An attempt was made to create an informal atmosphere so that the children felt free to ask questions, and thus allow an impression of overall content and face validity to be gauged by the researcher. Once the entire class had completed the questionnaire the children were questioned in small groups (three or four children) as to their comprehension of each question and their opinions on the overall test instrument, particularly content and format.

All data were analysed using SPSS for Windows version 6 .

\section{Results}

\section{Face and cognitive validity testing}

The initial studies resulted in a number of modifications in terms of phrasing, specific foods under study and graphic format. The post questionnaire discussion with a sample of respondents revealed that children found the inclusion of lines indicating the right number of answers (in the ingredients questions) helpful. An example question was included at the start of this section in the second draft of the pilot to highlight this.

\section{Reliability testing}

Following the above amendments, the original test questionnaire was repeated with the same cohort of children. In total, 37 children (17 male and 20 female) completed the revised version of the questionnaire. The main aim of the second test was for repeat reliability analysis. This analysis could not be undertaken on individual questions because of the altered phrasing, content and number of many questions. Instead the scores for the domains of knowledge of applied nutrition, knowledge of food preparation and perceived confidence for each section were correlated at time 1 and time 2 and showed that children generally achieved the same level of
Table 2 Internal reliability

\begin{tabular}{lcc}
\hline Component & $n$ & $\begin{array}{c}\text { Cronbach's } \\
\text { alpha }\end{array}$ \\
\hline Applied Nutrition Knowledge & 31 & $0.19^{\star \star \star}$ \\
Knowledge of Food Preparation & 31 & $0.56^{\star *}$ \\
$\quad$ Ingredients & & $0.69^{\star \star \star}$ \\
$\quad$ Time & 31 & $0.78^{\star \star *}$ \\
Perceived Confidence in Cooking Skills & 31 & \\
\hline
\end{tabular}

${ }^{\star *}, P<0.01 ;{ }^{* \star *}, P<0.001$.

score. Correlations for scores between times were significant (all $P<0.001$ ) at $0.458,0.577$ and 0.381 , respectively, for each of the domains. In the final questionnaire only two items failed to correlate significantly between time 1 and time 2 (ingredients in bread and perceived confidence to prepare meal items) in the food preparation section and no significant differences were demonstrated in any of the other components.

The internal reliability for each of the components for the final questionnaire is presented in Table 2. All results were significant, indicating good correlation of individual items with the total score for the component.

\section{Item analysis}

The item difficulty index for each item in the knowledge of applied nutrition section is presented in Table 3. In the final local piloting, questions on healthy snacks, healthy packed lunch and healthy proportions on the plate were answered correctly by more than $80 \%$, suggesting these questions were rather easy, whilst less than $20 \%$ were able to identify all four foods that health experts recommended eating more of (Table 3).

In item difficulty the questionnaire seemed somewhat less reliable at overall assessment of knowledge of food preparation, with less than $20 \%$ able to identify the ingredients for coleslaw, bread and lentil soup and the cooking times items. In general, item-total score correlations were again low in the items on food times (except for knowledge of time to cook pasta), indicating that they failed to distinguish between subjects scoring highly on the test and those with low scores.

In estimating discrimination index in the knowledge of applied nutrition section, only the item on healthy snack foods scored below 0.20 (cut-off point) (Table 3). In the local pilot, the items on healthy breakfast options, fruit and vegetable portions also scored low in discrimination scores so it was decided to reorganise the order of items. Further refinement on the possible choices in the answer categories was also made in these questions to reflect current local eating patterns. One question on packed lunches was added to reflect the content of the intervention.

A frequency distribution of the question on foods to increase/decrease (nine items in total required for full marks) revealed that $9 \%$ of the sample correctly identified 
Table 3 Item analysis for Knowledge of Applied Nutrition and Knowledge of Food Preparation

\begin{tabular}{lcc}
\hline Item & $\begin{array}{c}\text { Difficulty } \\
\text { (\% answering } \\
\text { correctly) }\end{array}$ & $\begin{array}{c}\text { Discrimination } \\
\text { (item-total } \\
r \text { value) }\end{array}$ \\
\hline Applied Nutrition Knowledge & 30 & 0.72 \\
$\quad$ Fruit and vegetable portions & 95 & 0.06 \\
Healthiest snack selection & 85 & 0.20 \\
Not healthy snack & 90 & 0.33 \\
Healthiest packed lunch fillings & 45 & 0.40 \\
Healthiest sandwich & 65 & 0.35 \\
Healthiest breakfast option & 95 & 0.36 \\
Meal proportions & 25 & 0.31 \\
Healthiest sandwich option & 70 & 0.63 \\
Healthiest potato option & 10 & 0.83 \\
Health experts recommend eat more of foods (9 items) & & 0.83 \\
Knowledge of Food Preparation* & 5 & 0.82 \\
Main ingredient of coleslaw & 15 & 0.73 \\
Main ingredient of lentil soup & 5 & 0.57 \\
Main ingredient of bread & 55 & \\
Main ingredient of apple crumble & 5 & \\
\hline
\end{tabular}

${ }^{*}$ Of the four questions on cooking times, $0 \%$ achieved $100 \%$ correct, $30 \%$ achieved $80 \%$ correct, $35 \%$ achieved $60 \%$ correct, $30 \%$ achieved $40 \%$ correct and $5 \%$ achieved $20 \%$ correct.

one of the five foods 'that people trying more healthful eating are recommended to eat more of', and 16\% scored all five.

Item discrimination index of knowledge of food preparation questions indicated that all of the items passed the item discrimination test, all being correctly answered by more than $20 \%$ of the sample, but not greater than $80 \%$.

The perceived confidence ratings (Table 4) showed a wide spread of responses, indicating few areas of high confidence. Boiled potatoes, boiled rice and pasta were the only items that around 50\% of respondents said they could prepare 'all by themselves'. This finding suggests there is considerable scope for improving confidence about cooking basic food items and the spread of responses implies that respondents feel able to use all options offered.

No changes were carried out on the questionnaire after the local (and final) pilot study, as it was felt that the majority of problem issues had been addressed and it was uneconomic to undertake further piloting for small refinements. Thus the final instrument contained a suitable

Table 4 Frequency distribution of perceived confidence ratings (\% of sample)

\begin{tabular}{lcccc}
\hline & $\begin{array}{c}\text { All by } \\
\text { myself }\end{array}$ & $\begin{array}{c}\text { With a } \\
\text { little help }\end{array}$ & $\begin{array}{c}\text { With a lot } \\
\text { of help }\end{array}$ & Not at all \\
\hline Stir-fry & 6.7 & 60.0 & 15.6 & 17.8 \\
Coleslaw & 31.1 & 33.3 & 20.0 & 15.6 \\
Boiled potatoes & 57.8 & 28.9 & 4.4 & 8.9 \\
Lentil soup & 28.9 & 40.0 & 17.8 & 13.3 \\
Apple crumble & 15.6 & 28.9 & 33.3 & 22.2 \\
Boiled rice & 51.1 & 35.6 & 6.7 & 6.7 \\
Pasta shells & 48.9 & 35.6 & 8.9 & 6.7 \\
Bread & 22.2 & 35.6 & 31.1 & 11.1 \\
Broccoli & 37.8 & 35.6 & 17.8 & 8.9 \\
\hline
\end{tabular}

range of questions for discriminating between high- and low-scoring subjects and a range of questions at a suitable difficulty level but including some relatively easy and some relatively difficult questions.

\section{Discussion}

In the present study, special attention was given to devising a questionnaire that could be completed by children from socially deprived inner city areas. The problems in measuring a multifaceted concept like nutrition knowledge may be particularly hard for children from socially disadvantaged backgrounds, where not only food choices differ, but experience with written text, linguistic code and varied levels of writing, reading, cognitive and conceptual skills may all vary considerably.

The food items queried were not necessarily representative of the complete range of food choices familiar to young people throughout the UK but were based on currently available data and a more recent report ${ }^{6}$ confirms that the food items selected are widely consumed by young people. Whilst the specific topics used in this test focused on foods familiar to children in the area where the interventions were planned, the instrument could easily be adapted for use in a multi-ethnic, multi-cultural setting providing the foods were familiar and cognitive testing demonstrated that children could grasp the questions being set, follow the instructions and respond appropriately. However, this instrument may be inappropriate for children with low literacy levels.

It is important to note that considerable effort was used in assessing face validity by asking the respondents to comment on the content and design of the measure, and noting errors in comprehension. Qualitative analysis (cognitive testing) helped further refine the questionnaire over and above an assessment of its 
psychometric properties alone and resulted in alteration of length, question format, nutritional criterion and ease of reading. This approach helped to ensure that the population under study comprehended what was being asked of them, were familiar with the terminology used and the subject matter on the test. This approach has been reported previously in studies of food and low income $^{26}$, and provides appropriate guidance for applying any new test in a target group from a different geographic region or population than from the original test setting. The overall reporting on the qualitative views suggested that further refinements to improve item analysis might in fact diminish comprehension and ease of use.

Despite rigorous quantitative and qualitative assessment and refinement of questionnaire design, some issues still remain over the use of questionnaires as instruments for reliably assessing knowledge over a period of time. Questioning in itself may alter post-intervention effects by making respondents more aware of nutritional information and their own food-related behaviours. The inclusion of a matched sample of control children in the present intervention design, however, should help to alleviate this problem.

This questionnaire was designed to assess practical knowledge as one of several tools used to evaluate a clubbased intervention aimed at improving knowledge about food, nutrition and dietary intake in children from a socially deprived background. We believe this tool could also be used without an intervention setting and may be useful in a schools-based programme on food studies that may (or may not) include practical cooking skills. It is likely to highlight gaps in knowledge that could support the re-introduction or maintenance of food skills programmes in schools.

Cooking is a practical skill intervention. The importance of using concrete experiences with food rather than abstract concepts should not be underestimated, as it is from these experiences that knowledge is actively constructed $^{12}$. Positive affective contexts and peer involvement have also been shown to increase food acceptance, preference and thus consumption ${ }^{27}$. Increasing familiarity with food through preparation and eating food prepared with peers in a positive affective context is a practical way to potentially increase nutrition knowledge, positive attitudes towards food, and consumption of 'more healthful' foods in line with current government recommendations. Evaluation of such interventions is necessary to assess the extent to which this potential is realised.

\section{Acknowledgements}

Permission for this study was granted by Dundee City Council Education Department and the staff of local schools. The work was undertaken by the authors with assistance from Ms Stacy. Funding was received under the Department of Health Nutrition Research Initiative; the views expressed in this publication are those of the authors and not necessarily those of the sponsor.

\section{References}

1 Caroline Walker Trust. Nutritional Guidelines for Schoolmeals. London: Caroline Walker Trust, 1993.

2 Freedman DS, Dietz WH, Srinivasaan SR, Berenson GS. The relation of overweight to cardiovascular risk factors among children and adolescents: the Bogalusa Heart Study. Pediatrics 1999; 103(6): 1175-82.

3 Adamson AJ, Rugg-Gunn AJ, Butler TJ, Appleton DR, Hackett AF. Nutritional intake, height and weight of 11-12 year old Northumbrian children in 1990 compared with information obtained in 1980. Br.J. Nutr. 1992; 68: 543-63.

4 Strain JJ, Robson PJ, Livingstone MB, Primrose ED, Savage JM, Cran GW, Boreham CA. Estimates of food and macronutrient intake in a random sample of Northern Ireland adolescents. Br. J. Nutr. 1994; 72(3): 343-52.

5 Hackett AF, Kirby S, Howie M. A national survey of the diet of children aged 13-14 years living in urban areas of the United Kingdom. J. Hum. Nutr. Diet. 1997; 10: 37-51.

6 Gregory J, Lowe S. National Diet and Nutrition Survey: Young People aged 4 to 18 years. London: The Stationery Office, 2000.

7 Moynihan PJ, Adamson AJ, Skinner R, Rugg-Gunn AJ, Appleton DR, Butler TJ. The intake of nutrients by Northumbrian adolescents from one-parent families and from unemployed families. J. Hum. Nutr. Diet. 1993; 6: 433-41.

8 Doyle W. Nutritional survey of schoolchildren in an inner city area. Arch. Dis. Child. 1994; 70: 376-81.

9 Michela JL, Contento IR. Cognitive, motivational, social, and environmental influences on children's food choices. Health Psychol. 1986; 5(3): 209-30.

10 Roe L, Hunt P, Bradshaw H, Rayner M. Health Promotion Interviews to Promote Healthy Eating in the General Population: A Review. London: Health Education Authority, 1997.

11 Lytle L, Achterberg C. Changing the diet of America's children: what works and why? J. Nutr. Educ. 1995; 27: 250-60.

12 Liquori T, Koch PD, Contento IR, Castle J. The Cookshop Program: outcome evaluation of a nutrition education program linking lunchroom food experiences with classroom cooking experiences. J. Nutr. Educ. 1998; 30: 302-13.

13 Parmenter K, Wardle J. Development of a general nutrition knowledge questionnaire for adults. Eur. J. Clin. Nutr. 1999; 53(4): 298-308.

14 Anderson AS, Campbell D, Shepherd R. Nutrition knowledge, attitude to more healthful eating and dietary intake in pregnant woman compared to non-pregnant woman. J. Hum. Nutr. Diet. 1993; 6: 335-53.

15 Health Education Authority (HEA)/Ministry of Agriculture, Fisheries and Food/Department of Health. Eight Guidelines for a Healthy Diet. London: HEA Customer Service, 1998.

16 Department of Health. Eat Well: Action Plan from the Nutrition Task Force to Achieve the Health of the Nation Targets on Diet and Nutrition. London: Department of Health, 1994.

17 Department of Health. Eat Well II: A Progress Report from the Nutrition Task Force on the Action Plan to Achieve the Health of the Nation Targets on Diet and Nutrition. London: Department of Health, 1996.

18 Anderson AS, Umpathy D, Palumbo LG, Pearson D. Nutrition knowledge assessed by a structured questionnaire 
in a group of medical inpatients. J. Hum. Nutr. Diet. 1988 1(1): 39-46.

19 Anderson AS, Bell A, Callander R. The impact of a nutrition education intervention to increase fruit and vegetable consumption in an area of urban deprivation. Proc. Nutr. SOC. 1999; 58: 1 .

20 Wrieden W. Evaluation of pilot schemes for catering in Dundee City Council schools. Unpublished report prepared for Dundee City Council, Tayside, 1998.

21 Gardner Merchant Ltd. What Are Today's Children Eating? The Gardner Merchant School Meals Survey. Surrey: Gardner Merchant Ltd, 1998.

22 McCance H, Widdowson EM. The Composition of Foods. London: HMSO, 1991.
23 Sudman S, Bradburn NM, Schwartz N. Thinking About Answers: The Application of Cognitive Process to Survey Methodology. San Francisco, CA: Jossey Bass, 1996.

24 Nunnally JC. Psychometric Theory, 2nd ed. New York: McGraw Hill, 1983.

25 Kline P. The Handbook of Psychological Testing. London: Routledge, 1993.

26 Alaimo K, Olsen CM, Frongillio E. Importance of cognitive testing for survey items: an example from food security questionnaires. J. Nutr. Educ. 1999; 31: 269-75.

27 Birch LL, Fisher JO. Development of eating behaviours among children and adolescents. Pediatrics 1998; 101: 539-49. 